pure occupational groups. No attempt was made to do this and there was no discussion of the purity of the ultimate occupational groups used for analysis. It is not, therefore, possible to accept the authors' conclusions concerning the occupational origin of abnormalities which they describe. However, their chief conclusion, namely that steel workers show a higher incidence of radiographic abnormalities than iron workers and that the highest incidence is in the fettling shop, may well be true as it confirms previous findings by the Silicosis and Asbestosis Medical Board and by other workers in this field.

A surprising frequency of slightly abnormal radiographs was observed in the younger workers. The authors suggest four entirely irrelevant explanations and do not mention the possibility that the interpretation of the radiographs, whose unreliability they have admitted, may be at fault.

Pattern shop workers, exposed only to wood dust, from their radiographs also showed evidence of dust inhalation. It is not possible to be certain of the cause or the reliability of the radiographic findings, since there is no discussion of the previous occupations of these men, nor of the observer error in interpreting such slight radiographic changes.

No important conclusions are derived from the spirometric and clinical investigations, and the observations on the incidence of tuberculosis in various occupational groups are not of much value, as no reference is made to the age distribution of men in the groups. The final conclusion is that the incidence of active tuberculosis is much the same as that found in the general population.

The account of the dust sampling investigations could have been given very briefly. A detailed analysis of the dust samples taken is difficult to justify in view of the authors' own opinion that "on account of the doubts and difficulties arising in the valuation of the samples and of the time and labour consumed in this work .... dust counts in iron foundries have a limited value". Similar criticism can be made of the publication of elaborate chemical analyses of both samples of dust, nearly the whole of which were of a particle size incapable of entering the lung.

In spite of its scientific and logical fallacies the report has its values but to claim that it contains a great deal of information of scientific value is hardly justified.

\section{M. Fletcher}

The Chemistry of Industrial Toxicology. By Hervey B. Elkins. 1950. New York: John Wiley \& Sons, Inc.; London : Chapman and Hall, Ltd. 24 illus., 366 refs. Pp. 406. Price 44s.

The Chemistry of Industrial Toxicology by Hervey B. Elkins is a good book. The author has drawn freely on his own experience in Massachusetts to pack its 406 pages with a great deal of valuable information.

The book is arranged in a logical manner that will appeal to the average practical chemist. It has clear and well labelled figures, particularly those in Chapter XVI, and its tables leave little to be desired. An attractive feature is the parallel recording of concen- tration with vapour pressure of certain substances, e.g., mercury (Table 6, p. 39), a time-saving aid to a chemist who has to give a quick and intelligible answer to his colleagues.

The references are representative and are obviously selected to aid further research, but it is a little exasperating to the reader to find more than thirty merely labelled "private communication" without always specifying the nature of the communicated subject matter.

Although most chemists tend to be individualists, they should attempt to incorporate in the current laboratory notebook any 'recent and time-saving modifications to a method which will help the assistants, particularly when these are semi-skilled and are faced with doing not tens but hundreds of analyses. It is, therefore, somewhat of a disappointment to find that relatively recent and tested methods have not always been mentioned, as for example, the use of solochrome brilliant blue B.S. in place of alizarin in the analysis of fluorine.

It is interesting to note that dinitro-para-cresol is described whereas dinitro-ortho-cresol is only mentioned. This may be justified because the former is used as a food-colouring agent in some countries, but as the latter is widely used as an insecticide, a little more information would be welcome, particularly in view of the paragraph which is devoted to a description of parathion and other organic phosphates.

On the whole, Chapter XVI on air sampling devices is informative and clearly set out. Since physicists are as much associated with industrial science as chemists, one would like to see a little more critical discussion of the electrostatic and thermal precipitation methods for dust collection. There is considerable divergence of opinion as to the practicability and reliability of the thermal method, particularly concerning the visual method of dust counting, which is liable to give variable results even with skilled workers. In view of this shortcoming there is an obvious need for more direct and reliable methods.

The inclusion of a chapter on fallacies and unsolved problems is a happy choice as it stimulates critical thought in a variety of ways, and the author, if he does not always attempt to offer solutions to some of the problems, leaves the reader with one or two useful openings. The comments on beryllium and amorphous silica stand out as examples.

The book is useful and informative, and although the cost may preclude possession by individual industrial chemists, it should form a useful addition to both chemical and medical industrial laboratories.

\section{Graham Harvey}

Recent Advances in Physical Medicine. Edited by Francis Bach. 1950. London : J. and A. Churchill Ltd. Illustrated. Pp. 490. Price 27s. 6d. net.

This volume is a collection of articles written by specialists under the editorship of Francis Bach. It shows the great development that has taken place in this department of medicine during the last 30 years. The old massage department of those days was the 